\title{
Towards Integrating Political Ecology into Resilience-Based Resource Management
}

\author{
Amy Quandt
}

Environmental Studies Program, University of Colorado-Boulder, 397 UCB, Boulder, CO 80309, USA; amy.quandt@colorado.edu; Tel.: +1-303-709-0038

Academic Editor: Alessandro Galli

Received: 7 August 2016; Accepted: 20 October 2016; Published: 26 October 2016

\begin{abstract}
One of the biggest challenges faced today is how to sustainably manage social-ecological systems for both ecological conservation and human wellbeing. This paper explores two approaches to understanding such systems: resilience thinking and political ecology. Resilience thinking is a framework that emerged over the last 40 years as a management strategy for social-ecological systems, and a resilient social-ecological system is capable of absorbing disturbances and still retaining its basic function and structure. Political ecology is derived from cultural ecology and political economy and aims to critically examine how human-environment interactions are linked to environmental problems while exploring issues of power. Drawing from debates and theoretical issues both within and between these two theories, this paper proposes three main arguments for integrating political ecology into managing for resilience. First, political ecology could help fill in understanding gaps in resilience with its focus on society and politics, while resilience thinking's focus on ecology can ensure that political ecology engages with ecology. Second, the multiple lenses of political ecology may help define the system for resilience management. Third, political ecology's explanatory power may assist in identifying surrogates of resilience for indirectly measuring social-ecological resilience.
\end{abstract}

Keywords: political ecology; resilience thinking; natural resources; resource management; environmental conservation

\section{Introduction}

One of the biggest challenges faced today by both natural resource managers and human development professionals is how to sustainably manage linked social-ecological systems for both ecosystem function and human wellbeing [1,2]. How can we maintain important ecosystem services and natural resources, while also allowing people to maintain their livelihoods? This paper explores two theoretical approaches that attempt to answer this question by informing the management of social-ecological systems: resilience thinking and political ecology.

The concepts of political ecology and resilience thinking have been compared and contrasted by scholars over the past 15 years [2-9]. Some continue to argue that they are fundamentally incompatible, largely because political ecologists and resilience scholars often come from different disciplines and schools of thought [7]. However, in a recent series of articles, Turner [7,9] explored connections between these frameworks and suggested that, despite barriers, resilience scholars and political ecologists maybe should work together in some cases [7]. For example, they hold congruent positions with respect to ecological responses to human land use, and political ecologists may be some of the best-placed social scientists to cooperate with resilience ecologists in understanding the complex interactions of history, human livelihood practices, and ecological responses [7].

This paper contributes to the work of Turner [7,9], Peterson [3], Brown [6], and others by identifying three specific points of synthesis between resilience thinking and political ecology. It aims 
to provide the theoretical basis for integrating political ecology and resilience thinking into research and resource management. These three insights are outlined in Figure 1.

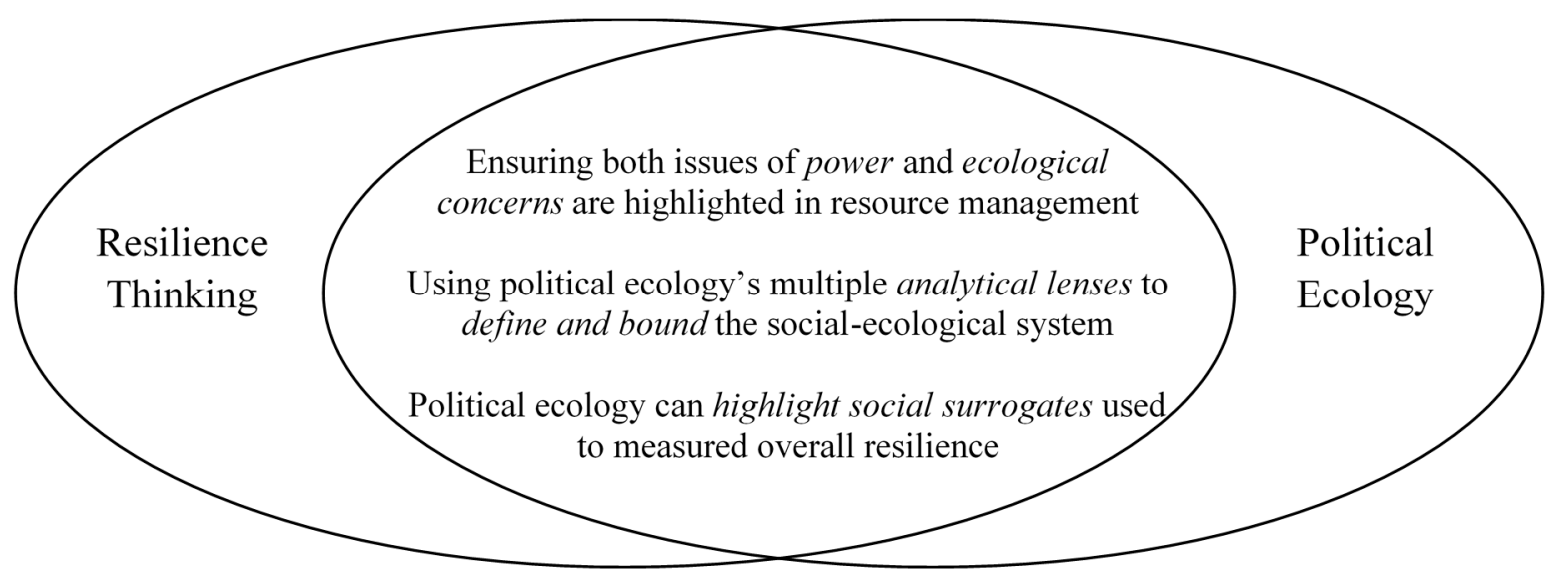

Figure 1. Major arguments towards integrating political ecology into resilience-based natural resource management.

\section{Resilience Thinking}

Before diving into the three insights of this paper, it is important to understand the major concepts embraced by resilience thinking. Resilience thinking has emerged over the last 40 years, originating in the field of ecology [10]. The concept was introduced as a technical ecological term by Holling [11] in research on spruce forest budworms. Originally, resilience thinking largely built upon insights from non-equilibrium ecology $[7,12]$. Over the years, resilience research has been expanded beyond the confines of its original ecological origins $[8,13]$. A resilience approach to social-ecological systems developed after the recognition that management systems based on optimization of a particular good or service (for example timber production) through getting rid of or altering change were not leading to either environmental or social sustainability [14]. Instead, resilience embraces change and uncertainty as part of the system in order to achieve sustainability. Resilience is often considered a 'boundary' concept that helps to integrate the natural and social aspects of sustainability [15]. Resilience thinking has now become popularized within a wide variety of academic disciplines as well as development organizations [16].

Resilience connotes multiple meanings that revolve around uncertainty, diversity, connectedness, change, persistence, structure, transformation, and agency [7]. Resilience is defined by Walker and Salt [14] as the capacity of a system to absorb disturbance and still retain its basic function and structure. For social-ecological systems, Cabell and Oelofse [17] define resilience as the capacity of a system to "maintain the ability to feed and clothe people in the face of shocks while building the natural capital base upon which they depend and provide a livelihood for the people who make it function" (p. 3). Other scholars include the idea of 'bouncing back and transforming after a disturbance' into their thinking of resilience [15]. Resilience can also be divided into general or specific resilience, where specified resilience asks the question "resilience of what and to what?" [14]. Because this can be a complicated question, the resilience approach requires interdisciplinary analysis and syntheses $[7,18]$.

Generally, resilience is associated with the systems' ability to recover from a disturbance [16]. Walker and Salt [14] explain the system as a ball in a basin. The ball is the current state of the system, and the basin is the system. If the ball crosses into another basin (due to fast or slow variables) it signifies that the system has crossed a threshold and entered into an alternative regime. The desired outcome of resilience management is to achieve a system that will provide continued sustainability of the economy, society, and natural resources [19]. A prominent aspect of the resilience approach to understanding and managing social-ecological systems is the complex adaptive cycle $[16,20,21]$. The adaptive cycle 
explains how the overall system adapts to change and uncertainty and exploits opportunities for growth [20]. The four phases of the adaptive cycle are rapid growth, conservation, release, and reorganization [14]. Rapid growth is the phase where species/people exploit new opportunities and available resources, followed by the conservation phase where connectedness of the system components increases and energy/materials accumulate. Next is the release phase where a disturbance or creative destruction causes the system to come undone, which leads to the reorganization phase where uncertainty, novelty, and innovation occur in the aftermath of a disturbance. The adaptive cycle happens at various scales; slower and larger levels set the conditions within which faster and slower ones function in a process called panarchy [20,22]. In panarchy, connections between levels can lead to events in faster/smaller cycles overwhelming slower/larger cycles, but it can also create cycles that remember past disturbance and make the system more resilient to disturbance in the future. A key to recovery is system memory where the social-ecological system can store and retrieve knowledge, either through individual recollection, or cultural practices, governments, and institutions $[5,23,24]$. The resilience of an ecosystem can be increased when the institutions governing that resource make effective decisions and utilize social memory and learning to manage natural resources [24]. An organization's or institution's ability to learn from the past is important in making management decisions that allow for change and adaptation. The complex adaptive system will never return to the precise structure and function as before a disturbance, but instead will renew, regenerate, and reorganize $[16,21]$.

\section{Political Ecology}

In order to understand how political ecology might be integrated into resilience-based resource management, it is important to understand what political ecology is and its major strengths. Unlike resilience thinking, political ecology is rooted in the social sciences. Political ecology began in the 1980s as a framework for understanding the complex interconnections between local people, global political economies, and ecosystems [25,26]. Political ecology emerged as a result of three convergent factors: cultural ecology, critical theory of many types, and that the apparent contradictions and feedbacks of global ecology appeared to be accelerating [27]. It aims to combine the concerns of ecology and political economy to represent the "tension between ecological and human change, and between diverse groups within society at scales from the local individual to the earth as a whole" [3] (p. 24). Political ecology research often focuses on critically examining established explanations for environmental problems and aims to "construct more meaningful and effective forms of explaining environmental problems" [28] (p. 24). An underlying assumption of political ecology is that politics and the environment are thoroughly interconnected and at the heart of political ecology is the idea that politics should be prioritized in any attempt to understand how human-environment interactions may be linked to environmental degradation [29].

Political ecology utilizes various academic theories, but it would be misleading to call it a theory itself [27]. Instead, it draws from a diversity of theories and schools of thought to explain complex environmental-social outcomes. Robbins [27] groups political ecology research into five dominant narratives: degradation and marginalization, conservation and control, environmental conflict and exclusion, environmental subjects and identity, and political objects and actors. Through these different narratives, political ecology aims to reveal winners and losers, hidden costs, and differential power that exists in social and environmental outcomes [27]. Some political ecology "tools" include common property theory, Marxist political economy, historical materialism, non-equilibrium ecology, traditional ecological knowledge, environmental and social justice, and critical environmental history [27,30]. Additionally, political ecology includes research on the sociology of science and knowledge, the history of institutions and policy dealing with the environment and development, the globalization of environmental discourses, and the power relationships of global environmental governance and management [31]. 
Two of the major strengths of political ecology are the focus on power and power relationships, and its local, case-based approach and ability to analyze human and environment relationships at various scales. Unlike other approaches to environmental problems, political ecology explicitly acknowledges the important role that political power and inequality of power play in environmental issues. Drawing from the work of Foucault [32,33], political ecology highlights the ways in which the power issues behind political representations, narratives, and discourses shape how people interact with the environment $[2,34]$. Politics and power are explored in political ecology both at the material level and the discursive level. For example, political entities can physically control natural resources (material level), while common narratives about environmental degradation can be used by those in power to maintain that power and control (discursive level). Political ecology research often traces the origins of narratives concerning the environment, with particular attention to identifying power relationships, and how these relationships affect the ecology, economic, and social aspects of an environmental issue [29,31]. In political ecology these power relationships and hierarchical connections are explored at multi-scalar levels from the local to the global. Political ecology's place-based approach allows for a deep understanding of the historical and political context behind contemporary patterns of resource use and environmental degradation [9]. It often also aims to connect larger-scale global and regional political, economic, and ecological processes to specific, situated, case studies.

The previous sections have provided brief summaries of both resilience thinking and political ecology (as seen in Table 1). In the next section, I will outline the major debates and critiques of resilience thinking and political ecology. Drawing from these debates and critiques, the remainder of the paper will provide some specific ways that integrating political ecology approaches into resilience thinking potentially creates a more complete, effective understanding of environmental issues and management solutions. I am not saying that these methods are completely compatible or should always be used in tandem. According to Turner [7], political ecologists are some of the first to criticize the management methods of resilience thinking as "top-down" due to political ecology's commitments to environmental and social justice. However, political ecologists may be some of the best social scientists to collaborate with resilience-based managers because of their emphasis and understanding of complex interactions in history, livelihoods, and ecological responses to these histories and livelihoods [7]. Additionally, political ecology is largely an explanatory field [28], and while it can inform management, it is not a management framework like resilience thinking is.

Table 1. Key characteristics for the two approaches for understanding social-ecological systems discussed in this paper.

\begin{tabular}{cc}
\hline Approaches & Key Characteristics \\
\hline $\begin{array}{c}\text { Resilience Thinking } \\
\text { Revolves around uncertainty, diversity, connectedness, change, persistence, transformation } \\
\text { Complex adaptive cycle: rapid growth, conservation, release, and reorganization } \\
\text { Panarchy concept connects cycles at various scales } \\
\text { The social-ecological system is a ball in a basin }\end{array}$ \\
$\begin{array}{c}\text { Capacity of a system to absorb disturbance and still retain its basic function and structure [14] } \\
\text { Political Ecology } \\
\text { Understanding the connections between people, political economies, and ecosystems [25,26] } \\
\text { Combines concerns of political economy and human ecology [27] }\end{array}$ \\
Emphasis on historical and political context of resource use and environmental degradation \\
Place-based, focus on case studies \\
Multi-scalar \\
Acknowledges the role power and power relationships play in environmental issues \\
Politics and the environment are thoroughly connected
\end{tabular}

\section{The Debates}

While both resilience thinking and political ecology have their strengths in analyzing social-environmental problems, they also have their weaknesses or critiques. Resilience thinking has been criticized for being difficult to operationalize [17], hard to measure [10], not fully integrating the social dimensions [21], not acknowledging the power relationships within a social-ecological 
system [35,36], being difficult to define the scales of analysis, and being challenging to put boundaries around the system [37]. To manage for resilience it is important to understand the social-ecological system with particular attention to the drivers that cause it to cross thresholds between alternative regimes, and how to enhance aspects of the system that enable it to maintain or build its resilience [14]. This is essentially a problem definition exercise which asks the questions: what aspects of the system should be resilient and what kinds of change would we like the system to be resilient to [38]? However, answering these questions is difficult and poses a big hurdle for resilience thinking because resilience is contingent on social values regarding what is deemed important [7].

Measuring resilience is also a difficult task, although several authors have put forward ideas about how to empirically measure resilience $[5,10,14,17,35,36,38-41]$. Because resilience is not something that can be empirically measured, most researchers have been attempting to define surrogates or indicators of resilience as a proximate measure of resilience. However, there is no standard protocol for determining surrogates of resilience, nor should there be. Instead, a comprehensive strategy for ensuring that major social and ecological aspects of resilience are included for measurement protocols is important. One last major critique of resilience thinking is that it has grown in isolation from social science research on the human dimensions of environmental change, and instead mainly evolved through the application of ecological concepts to society [4]. This creates problems because it may assume that social and ecological system dynamics are similar [4]. For example, Cote and Nightingale [4] state that the "reliance on ecology principles to analyze social dynamics has led to a kind of social analysis that hides the possibility to ask important questions about the role of power and culture in adaptive capacity."

Political ecology has also been debated and critiqued. For example, political ecology has been repeatedly critiqued for being unengaged with ecology and the biophysical world [42-44]. Vayda and Walters [42] accuse political ecologists of "only dealing with politics, albeit politics somehow related to the environment" (p. 168). As stated above, dealing with politics and power is a strength of political ecology; nevertheless, political ecology research that only focuses on politics and power is critiqued for missing the ecological aspects of environmental change. Even though this critique is not new, in a review of current political ecology research Turner [9] finds that work actively engaging in ecology is still only a minority of political ecology research. However, this critique is based on the assumption that political ecology should engage directly with ecology in the first place to conduct successful analysis of human-environment interactions.

Using political ecology to complement resilience thinking can help address the critiques of each of these methods for understanding human-environment interactions. There is significant value added to the analysis when political ecology is integrated into resilience-based management because of its ability to understand the interactions of history, livelihoods, and the environment. Specifically, I will focus on three key insights to why integrating political ecology into resilience-based management could lead to more effective resource management. First, the ecological origins of resilience thinking can address the need for political ecology to engage with ecology, while the political focus of political ecology can help integrate social aspects into resilience thinking. Second, political ecology's ability to focus on situated case studies may help define the system, its scale, and boundaries, which is something that challenges resilience thinking. Third, political ecology's explanatory power may help define surrogates or indicators of resilience. Political ecology looks at environmental issues through many lenses (political, social, cultural, economic, etc.) and these various lenses may identify specific measures of resilience in a holistic and effective way.

\section{Where Is the Ecology? Where Is the Politics?}

The integration of the social dimensions of the social-ecological system in resilience thinking has been a slow process, but it is important for understanding change and managing for resilience in social-ecological systems [6,21,45]. Cote and Nightingale [4] define social resilience as the ability of communities to cope with stresses as a result of social, political, or environmental change. 
This definition is, however, quite vague and the word "community" can be a highly contested and misunderstood term. Agrawal and Gibson [46] assert that "community" should not be viewed as a small spatial unit with a homogenous population, but instead it should be viewed through a political lens as a heterogeneous group of actors with multiple interests and varied levels of influence on decision-making processes and institutions [46]. Political ecology may provide the proper analytical tools to shed light on power relationships and hierarchies present in communities that are part of social-ecological systems. Power relationships may influence people's ability to adapt to change and manage the system to be more resilient to shocks and disturbances. For example, power inequalities between genders may shape their abilities to adapt to climate risks [47]. Power inequalities could include inequalities in participation in decision-making, the division of labor, resource access and control, and knowledge and skills [36]. Political ecology could help improve the understanding of any power inequalities and their causes, and therefore illustrate how they might be important in social-ecological resilience management [48].

Another question of power when managing for resilience is who gets to decide the resilience of what and to what? Who has power in this process of determining the desired outcomes of resilience management is important for understanding how these decisions are made [35,36]. For example, as Nadasdy [49] explains, even though native people may possess rich knowledge about their environment, power to manage the environment often lies in the hands of natural resource managers, and integrating these types of knowledge and different management perspectives is difficult. Political ecology can highlight these challenges: that some people gain while others lose in the process of resilience building, and that resilience for some people or places could lead to the loss of resilience for other social-ecological systems [8]. This is important in effective resilience-based management. As Haraway [50] explains, all knowledge is situated and there are a multiplicity of knowledges that exist, and therefore each stakeholder may have different knowledge and perspectives about how an area should be managed for resilience. Political ecology could assist natural resource managers make sense of power relationships between stakeholders. By uncovering and highlighting hierarchies of power and suppressed knowledge, it can help uncover the various situated knowledge that exists about a particular social-ecological system and how it functions. Political ecology can help natural resource managers incorporate "non-scientific" knowledge into management and planning by first showing that they exist, and second illustrating their importance to natural resource management.

Alternatively, utilizing political ecology and resilience thinking in tandem when trying to understand a social-ecological system can help enhance the ecological understanding and analysis of the system. Resilience thinking emerged from the field of ecology [14], often uses ecological terms, and aims for a thorough understanding of the ecosystems involved in management [20]. For example, resilience thinking explicitly acknowledges that different ecosystem processes occur at different rates, and that both stabilizing and destabilizing forces can be important for ecosystem function [20]. Taking into account how ecological processes may influence politics, economics, and society is important to integrate into political ecology analyses because it can provide a more thorough understanding. For example, understanding what role a long-term drought and its impacts on the ecosystem (i.e., water availability, vegetation growth, and temperature) might play in local politics or economies would be an important component for understanding the system. In empirical research, drought as an ecological process, has been shown to impact social and political processes, leading to conflict [51]. Both resilience thinking and political ecology can benefit from utilizing analytical tools from one another to address critiques in each.

\section{Defining the Social-Ecology System}

Political ecology may assist in defining the social-ecological system for resilience-based management. Resilience practitioners need to define the system they are working with and set boundaries. This is an involved and difficult step in resilience-based management. Cumming et al. [18] propose a research design for studying resilience which includes defining the current system, defining 
possible future systems, clarifying change trajectories, assessing likelihoods of alternate futures, and identifying mechanisms for change. In all these steps, understanding the system and its boundaries is incredibly important. While this may sound simple, defining the boundaries of the system is difficult for any theory, including both political ecology and resilience thinking.

However, utilizing political ecology in a resilience-based approach to natural resource management may be able to help answer such questions about how to define the system, where thresholds lie, and what factors cause a social-ecological system to shift to an alternative regime. For example, it may be impossible or unethical to induce a system to cross a threshold in order to understand where the threshold lies and what factors could cause the system to cross a threshold. However, political ecology could help uncover and assess thresholds retrospectively, through a detailed historical analysis of the system and its major components [40]. For example, in a review of empirical research, Forsyth [28] discusses how some political ecology case studies have shown that, historically, some shifting cultivators have increased biodiversity by introducing regular forest disturbance, and have thereby not caused the system to cross a threshold towards decreased biodiversity. More broadly speaking, Peterson [3] proposes that a political ecology approach to resilience could help in determining the interconnected dynamics of a system, which would then allow for an assessment of when a system is more vulnerable, or when it is most open for transformation. Here, political ecology may be used to better define the social-ecological system in order to understand what variables are changing and how that might provide an opportunity for building resilience, or understanding how the system is vulnerable to change. Additionally, political ecology draws on the field of hazards research, where management systems which may be geared to minimize risk to natural hazards can be altered by political or economic pressure [27]. This political ecology tool relates directly to resilience thinking because it examines how social-ecological systems deal with various types of shocks, which could inform how to manage such systems for resilience to hazards.

To effectively define the system, Cote and Nightingale [4] propose that political ecology, with its focus on the human dimensions of environmental change, can examine the socio-cultural contexts present underlying the heterogeneities across different system dynamics. The context of each social-ecological system is important $[40,52]$ and political ecology can help define the social and historical contexts of the system. For example, Goldman [53] used political ecology to explain how the conservation concept of wildlife corridors is embedded in politics and the history of relations between local people and foreign conservation organizations. In defining the system, it may also be necessary to understand the various scales influencing the system and how to draw boundaries around the social-ecological system of interest. But where should the boundary be drawn? Previous research in both political ecology and resilience draws from case studies, and utilizing and combining the knowledge and experience from these cases could help better inform managers how to define the social-ecological system.

A key for drawing boundaries around a social-ecological system is having an understanding of which factors that influence the system can be controlled and which cannot. This is where a political ecology approach might help determine the more proximate (and controllable) components of the system, giving managers and communities a starting place when thinking about resilience. However, acknowledging components of the system that may lie outside the determined proximate boundaries is important to understanding how 'outside' factors influence the system and could contribute to or degrade social-ecological resilience. Drawing boundaries deals with issues of scale and at which scale the system will be defined. Brown and Purcell [37] discuss how political ecology has been used in analysis of the wider political economy so that the local scale can be analyzed in its wider scalar context. This type of analysis may help manage resilience at a local scale because it can illustrate how the system fits into a wider scalar context. Political economy, culture, and ecology all exist and operate simultaneously at a range of scales, and acknowledging this is important. Identifying the important components for resilience must take into consideration at which scale these components exist and how they interact across scales. 


\section{Measuring Resilience}

The last insight is how political ecology can assist resilience-based managers to better measure resilience. Focusing on surrogates or indicators of resilience acknowledges that important aspects of resilience in social-ecological systems may not be directly observed or measured, but instead must be inferred indirectly [40]. This creates a serious challenge to resilience management. Indicators have been used extensively in ecological research but resilience indicators are different because they apply to the entire system, both social and ecological. Indicators also focus on variables that underlie the capacity of the system to provide ecosystem services, and not just the current state of the system [10]. According to Carpenter et al. [40] there are four general approaches that have been utilized by researchers, and these could benefit from a political ecology approach. The first is stakeholder assessments where aspects of social-ecological resilience are identified through stakeholder workshops aimed at building a common understanding of change in the system. Political ecology would be useful in stakeholder assessments because it could help identify who the stakeholders are in the first place and what the power relationships are between stakeholders. The second approach in determining surrogates is model explorations where models of systems are used to explore the potential thresholds for change, and identify measurable aspects of the system. Political ecology can help develop models of the system by adding to the understanding of the different political, economic, and cultural components and how they are interrelated at various scales. The third approach is historical profiling where a history of the social-ecological system is assessed to classify various alternative system regimes and analyze events in the past that have caused transitions in the system. Political ecology is often used to understand the nuances of the historical context of environmental and/or development issues and it may be able to do the same here in determining surrogates of resilience. Understanding how the social or ecological aspects of the system have changed in the past can help to understand how it might change in the future and what causes these changes. Lastly, the fourth approach to identifying surrogates of resilience is case study comparisons where social-ecological systems that have similarities, but appear to be changing in different ways, are examined to assess properties related to resilience. Comparing case studies allows us to understand how they are different, and therefore what factors might be adding to resilience. The field of political ecology has often focused on case studies to understand human-environment interactions, which makes political ecology particularly useful in this approach. Political ecology has proven insightful when analyzing case studies for what are the drivers of environmental or livelihood degradation [28].

\section{Conclusions}

As this paper has outlined, using a political ecology analysis in resilience-based management may lead to more effective management of social-ecological systems that addresses debates and critiques of both approaches. First, utilizing political ecology and resilience thinking in tandem answers the problem of either approach being too focused on either politics or ecology, and ignoring the other. Second, political ecology's multiple analytical lenses, ability to provide historical context, and case-study nature may help resilience thinking better define and bound the social-ecological system. Lastly, political ecology can highlight social, political, or livelihood dimensions of the system that should be used as a surrogate of resilience when measuring overall social-ecological resilience.

The world around us is changing at a rapid pace and this may be negatively impacting people around the globe; in particular, climate change is expected to have serious consequences [54]. Understanding the interconnectedness of nature and society is critical to dealing with a changing world and managing for change [55]. Using a political ecology-informed resilience thinking framework for social-ecological system management provides one potential approach for managing resources for change and ensuring that systems can continue to provide ecosystem services and productive livelihoods to the people who depend on them. 
Acknowledgments: This manuscript has no funding sources. The author would like to acknowledge Mara Goldman, J. Terrence McCabe, and three anonymous reviewers for their feedback on previous drafts of this manuscript.

Conflicts of Interest: The author declares no conflict of interest.

\section{References}

1. Berkes, F.; Colding, J.; Folke, C. (Eds.) Navigating Social-Ecological Systems: Building Resilience for Complexity and Change; Cambridge University Press: Cambridge, UK, 2003.

2. Fabinyi, M.; Evans, L.; Foale, S.J. Social-ecological systems, social diversity, and power: Insights from anthropology and political ecology. Ecol. Soc. 2014, 19. [CrossRef]

3. Peterson, G. Political ecology and ecological resilience: An integration of human and ecological dynamics. Ecol. Econ. 2000, 35, 323-336. [CrossRef]

4. Cote, M.; Nightingale, A.J. Resilience thinking meets social theory: Situating social change in socio-ecological systems (SES) research. Prog. Hum. Geog. 2012, 36, 475-489. [CrossRef]

5. Leslie, P.; McCabe, J.T. Response diversity and resilience in social-ecological systems. Curr. Anthropol. 2013, 54, 114-143. [CrossRef] [PubMed]

6. Brown, K. Global environmental change 1: A social turn for resilience? Prog. Hum. Geog. 2014, 38, $107-117$. [CrossRef]

7. Turner, M.D. Political ecology I: An alliance with resilience? Prog. Hum. Geog. 2014, 38, 616-623. [CrossRef]

8. Stone-Jovicich, S. Probing the interfaces between the social sciences and social-ecological resilience: Insights form integrative and hybrid perspectives in the social sciences. Ecol. Soc. 2015, 20. [CrossRef]

9. Turner, M.D. Political ecology II: Engagements with ecology. Prog. Hu. Geog. 2016, 40, 1-9. [CrossRef]

10. Carpenter, S.; Walker, B.; Anderies, M.; Abel, N. From metaphor to measurement: Resilience of what to what? Ecosystems 2001, 4, 765-781. [CrossRef]

11. Holling, C.S. Resilience and stability of ecological systems. Annu. Rev. Ecol. Syst. 1973, 4, 1-23. [CrossRef]

12. McIntosh, R.P. Pluralism in ecology. Annu. Rev. Ecol. Syst. 1987, 18, 321-341. [CrossRef]

13. Beichler, S.A.; Hasibovic, S.; Davidse, B.J.; Deppisch, S. The role played by social-ecological resilience as a method of integration in interdisciplinary research. Ecol. Soc. 2014, 19. [CrossRef]

14. Walker, B.; Salt, D. Resilience Thinking: Sustaining Ecosystems and People in a Changing World; Island Press: Washington, DC, USA, 2006.

15. Olsson, L.; Jerneck, A.; Thoren, H.; Persson, J.; O’Bryne, D. Why resilience is unappealing to social science: Theoretical and empirical investigations of the scientific use of resilience. Sci. Adv. 2015, 1. [CrossRef] [PubMed]

16. Fath, B.D.; Dean, C.A.; Katzmair, H. Navigating the adaptive cycle: An approach to managing the resilience of social systems. Ecol. Soc. 2015, 20. [CrossRef]

17. Cabell, J.F.; Oelofse, M. An indicator framework for assessing agroecosystem resilience. Ecol. Soc. 2012, 17. [CrossRef]

18. Cumming, G.S.; Barnes, G.; Perz, S.; Schmink, M.; Sieving, K.E.; Southworth, J.; Binford, M.; Holt, R.D.; Stickler, C.; Van Holt, T.; et al. An exploratory framework for the empirical measurement of resilience. Ecosystems 2005, 8, 975-987. [CrossRef]

19. Walker, B.; Carpenter, S.; Anderies, J.; Abel, N.; Cumming, G.; Janssen, M.; Lebel, L.; Norberg, J.; Peterson, G.; Pritchard, R. Resilience Management in Social-Ecological Systems: A Working Hypothesis for a Participatory Approach. Available online: http://www.ecologyandsociety.org/vol6/iss1/art14/ (accessed on 2 July 2016).

20. Gunderson, L.; Holling, C.S. Panarchy: Understanding Transformation in Human and Natural Systems; Island Press: Washington, DC, USA, 2002.

21. Folke, C. Resilience: The emergence of a perspective for social-ecological systems analyses. Glob. Environ. Chang. 2006, 16, 253-267. [CrossRef]

22. Holling, C.S.; Gunderson, L.H.; Peterson, G.D. Chapter three: Sustainability and panarchies. In Panarchy: Understanding Transformation in Human and Natural Systems; Gunderson, L.H., Holling, C.S., Eds.; Island Press: Washington, DC, USA, 2002.

23. Berkes, F.; Seixas, C.C. Building resilience in lagoon social-ecological systems: A local-level perspective. Ecosystems 2005, 8, 967-974. [CrossRef] 
24. Hahn, T. Self-Organized Governance Networks for Ecosystem Management: Who Is Accountable? Available online: http://www.ecologyandsociety.org/vol16/iss2/art18/ (accessed on 2 July 2016).

25. Blaikie, P.; Brookfield, H. Land Degradation and Society; Methuen: MA, USA, 1987.

26. Schmink, M.; Wood, C.H. The political ecology of Amazonia. In Lands at Risk in the Third World: Local Level Perspectives; Little, P., Horowitz, M., Eds.; Westview Press: Boulder, CO, USA, 1987.

27. Robbins, P. Political Ecology: A Critical Introduction; John Wiley and Sons: Hoboken, NJ, USA, 2012.

28. Forsyth, T. Critical Political Ecology: The Politics of Environmental Science; Routledge: New York, NK, USA, 2009.

29. Bryant, R.L. Power, knowledge and political ecology in the third world: A review. Prog. Phys. Geog. 1998, 22, 79-94. [CrossRef]

30. Zimmerer, K.; Bassett, T. Political Ecology: An Integrative Approach to Geography and Environment-Development Studies; Guilford Press: New York, NY, USA, 2003.

31. Adger, W.N.; Benjaminsen, T.A.; Brown, K.; Svarstad, H. Advancing a political ecology of global environmental discourses. Dev. Chang. 2001, 32, 681-715. [CrossRef]

32. Foucault, M. Archeology of Knowledge; Tavistock: London, UK, 1972.

33. Foucault, M. Power/Knowledge: Selected Interviews and Other Writings 1972-1977; Vintage: London, UK, 1980.

34. Agrawal, A. Environmentality: Technologies of Government and the Making of Subjects; Duke University Press: Durham, NC, USA, 2005.

35. Lebel, L.; Anderies, J.M.; Campbell, B.; Folke, C.; Hatfield-Dodds, S.; Hughes, T.P.; James, W. Governance and the Capacity to Manage Resilience in Regional Social-Ecological Systems. Available online: http:/ / www.ecologyandsociety.org/vol11/iss1/art19/ (accessed on 3 June 2016).

36. Nelson, V.; Stathers, T. Resilience, power, culture, and climate: A case study from semi-arid Tanzania, and new research directions. Gend. Dev. 2009, 17, 81-94. [CrossRef]

37. Brown, J.C.; Purcell, M. There's nothing inherent about scale: Political ecology, the local trap, and the politics of development in the Brazilian Amazon. Geoforum 2005, 36, 607-624. [CrossRef]

38. Bennett, E.M.; Cumming, G.W.; Peterson, G.D. A systems model approach to determining resilience surrogates for case studies. Ecosystems 2005, 8, 945-957. [CrossRef]

39. Anderies, J.M.; Janssen, M.A.; Ostrom, E. A Framework to Analyze the Robustness of Social-Ecological Systems from an Institutional Perspective. Available online: http://www.ecologyandsociety.org/vol9/iss1/ art18/ (accessed on 24 May 2016).

40. Carpenter, S.R.; Westley, F.; Turner, M.G. Surrogates for resilience of social-ecological systems. Ecosystems 2005, 8, 941-944. [CrossRef]

41. Nadasdy, P. Adaptive co-management and the gospel of resilience. In Adaptive Co-Management: Collaboration, Learning, and Multilevel Governance; Armitage, D., Berkes, F., Doubleday, D., Eds.; University of British Columbia Press: Vancouver, BC, Canada, 2007.

42. Vayda, A.P.; Walters, B.B. Against political ecology. Hum. Ecol. 1999, 27, 167-179. [CrossRef]

43. Castree, N. Nature; Routledge: New York, NY, USA, 2005.

44. Bakker, M.; Bridge, G. Material worlds? Resource geographies and the 'matter of nature'. Prog. Hu. Geog. 2006, 30, 2-5. [CrossRef]

45. Perrings, C. Resilience in the dynamics of economy-environment systems. Environ. Resour. Econ. 1998, 11, 503-520. [CrossRef]

46. Agrawal, A.; Gibson, C.C. Enchantment and disenchantment: The role of community in natural resource conservation. World Dev. 1999, 27, 629-649. [CrossRef]

47. Rossi, A.; Lambrou, Y. Gender and Equity Issues in Liquid Biofuels Production: Minimizing the Risks to Maximize the Opportunities; Food and Agriculture Organization: Rome, Italy, 2008.

48. Phadke, R. Reclaiming the technological imagination: Water, power, and place in India. In Knowing Nature: Conversations at the Intersection of Political Ecology and Science Studies; Goldman, M.J., Nadasdy, P., Turner, M.D., Eds.; The University of Chicago Press: Chicago, IL, USA, 2011.

49. Nadasdy, P. The anti-politics of TEK: The institutionalization of co-management discourse and practice. Anthropologica 2005, 47, 215-232.

50. Haraway, D. Situated knowledges: The science question in feminism and the privilege of partial perspective. Feminist Stud. 1988, 14, 575-599. [CrossRef] 
51. Linke, A.M.; O’Loughlin, J.; McCabe, J.T.; Tir, J.; Witmer, F.D. Rainfall variability and violence in rural Kenya: Investigating the effects of drought and the role of local institutions with survey data. Glob. Environ. Chang. 2015, 34, 35-47. [CrossRef]

52. Holling, C.S. Understanding the complexity of economic, ecological and social systems. Ecosystems 2001, 4, 390-405. [CrossRef]

53. Goldman, M. The politics of connectivity across human-occupied landscapes: Corridors near Nairobi National Park, Kenya. In Knowing Nature: Conversations at the Intersection of Political Ecology and Science Studies; Goldman, M.J., Nadasdy, P., Turner, M., Eds.; The University of Chicago Press: Chicago, IL, USA, 2011.

54. Pahl-Wostl, C. Transitions towards adaptive management of water facing climate and global change. Water Resour. Manag. 2007, 21, 49-62. [CrossRef]

55. Harvey, D. The nature of the environment: The dialects of social and environmental change. Soc. Regist. 1993, 29, 1-51.

(C) 2016 by the author; licensee MDPI, Basel, Switzerland. This article is an open access article distributed under the terms and conditions of the Creative Commons Attribution (CC-BY) license (http://creativecommons.org/licenses/by/4.0/). 